\title{
A Cardiac Variant of Fabry Disease Diagnosed with Chance Urinary Mulberry Cells
}

\author{
Rina Onishi ${ }^{1}$, Koshiro Kanaoka ${ }^{1,2}$, Junichi Sugiura ${ }^{1}$, Motoko Tokunaga ${ }^{1}$, Yasuhiro Takemoto ${ }^{1}$, \\ Kenji Onoue $^{2}$, Yuta Yamamoto ${ }^{1}$, Manabu Horii ${ }^{1}$ and Yoshihiko Saito ${ }^{2}$
}

\begin{abstract}
:
Fabry disease is an X-linked lysosomal storage disorder caused by a deficiency of $\alpha$-galactosidase A and is classified into two types: classical and variant. The classical type exhibits classic manifestations, but the variant type does not and is therefore difficult to identify sometimes. A 73-year-old woman with a first episode of heart failure was admitted to our hospital. Her left ventricular wall motion was mildly reduced without hypertrophy. Urine sediment revealed mulberry cells, leading to the diagnosis of Fabry disease. In cases without typical clinical findings, urinary mulberry cells may help diagnose Fabry disease.
\end{abstract}

Key words: fabry disease, mulberry body, mulberry cell, cardiac variant

(Intern Med 57: 3385-3388, 2018)

(DOI: 10.2169/internalmedicine.1177-18)

\section{Introduction}

Fabry disease is an X-linked lysosomal storage disorder caused by a deficiency of $\alpha$-galactosidase A ( $\alpha$-GAL) that leads to globotriaosylceramide (GL-3) deposition in many tissues (1).

Fabry disease is classified into two types: classical and variant. Patients with classical type present with peripheral neuropathy, abdominal pain, nausea, and hypohidrosis during childhood; cardiac disease, renal disease, and cerebrovascular disease can develop during adulthood. Conversely, those with variant type lack such classic manifestations because the residual enzyme activity slows the disease progression. Therefore, patients with Fabry disease exhibit various phenotypes, including cardiac, renal, or cerebrovascular diseases.

We herein report a case of cardiac variant of Fabry disease diagnosed by the presence of urinary mulberry cells.

\section{Case Report}

A 73-year-old woman treated for rheumatoid arthritis was admitted to our hospital because of worsening dyspnea and bilateral lower extremity edema. She had no history of heart failure, chronic kidney disease, hypohidrosis, or peripheral pain. She had been prescribed methotrexate $4 \mathrm{mg}$ weekly, and prednisolone $3 \mathrm{mg}$ and etodolac $400 \mathrm{mg}$ daily.

On examination, her blood pressure, heart rate, and percutaneous oxygen saturation were 124/66 mmHg, 74 beats/min (regular sinus rhythm), and $98 \%$, respectively. A physical examination showed decreased bilateral pulmonary sounds and bilateral pitting edema in the legs. A neurological examination revealed no abnormalities such as peripheral nervous system disorders.

Table shows the laboratory data on admission: blood urea nitrogen level, $20.0 \mathrm{mg} / \mathrm{dL}$; serum creatinine level, $1.13 \mathrm{mg} /$ dL; N-terminal pro-brain natriuretic peptide level, 6,749 pg/ $\mathrm{mL}$; and D-dimer level, $4.6 \mu \mathrm{g} / \mathrm{mL}$. A urinalysis showed no sugar, protein, or red blood cells. Chest radiography revealed small bilateral pleural effusions. A 12-lead electrocardiogram showed a normal sinus rhythm, left axis deviation, and poor $\mathrm{R}$ wave progression in the precordial leads. Echocardiography revealed global left ventricular hypokinesis with a left ventricular ejection fraction of $30 \%$. The interventricular septum thickness was $7.2 \mathrm{~mm}$, and the left ventricular posterior wall thickness was $8.1 \mathrm{~mm}$ with the presence of a thrombus inside of the left ventricle (Fig. 1). Coronary computed tomography angiography showed no obvious stenoses in the coronary arteries.

${ }^{1}$ Cardiovascular Medicine, Nara City Hospital, Japan and ${ }^{2}$ Cardiovascular Medicine, Nara Medical University, Japan 
The patient was diagnosed with heart failure and administered azosemide and enarapril. Her symptoms gradually improved, and she was prescribed carvedilol. During hospitalization, urinary sediment revealed the presence of mulberry

Table. Laboratory and Urine Tests on Admission.

\begin{tabular}{|c|c|}
\hline \multicolumn{2}{|c|}{ Complete blood count } \\
\hline WBC & $93.3 \times 10^{2} / \mu \mathrm{L}$ \\
\hline $\mathrm{RBC}$ & $489 \times 10^{4} / \mu \mathrm{L}$ \\
\hline HGB & $14 \mathrm{~g} / \mathrm{dL}$ \\
\hline PLT & $29 \times 10^{4} / \mu \mathrm{L}$ \\
\hline \multicolumn{2}{|l|}{ Chemistry } \\
\hline AST & $39 \mathrm{U} / \mathrm{L}$ \\
\hline ALT & $32 \mathrm{U} / \mathrm{L}$ \\
\hline $\mathrm{TP}$ & $7.9 \mathrm{~g} / \mathrm{dL}$ \\
\hline Alb & $4.2 \mathrm{~g} / \mathrm{dL}$ \\
\hline T-Bil & $1.4 \mathrm{mg} / \mathrm{dL}$ \\
\hline BUN & $20 \mathrm{mg} / \mathrm{dL}$ \\
\hline Cre & $1.13 \mathrm{mg} / \mathrm{dL}$ \\
\hline eGFR & $36.6 \mathrm{~mL} / \mathrm{min} / 1.73 \mathrm{~m}^{2}$ \\
\hline UA & $4.7 \mathrm{mg} / \mathrm{dL}$ \\
\hline $\mathrm{Na}$ & $147 \mathrm{mmol} / \mathrm{L}$ \\
\hline $\mathrm{K}$ & $3.6 \mathrm{mmol} / \mathrm{L}$ \\
\hline $\mathrm{Cl}$ & $101 \mathrm{mmol} / \mathrm{L}$ \\
\hline TG & $118 \mathrm{mg} / \mathrm{dL}$ \\
\hline Glucose & $116 \mathrm{mg} / \mathrm{dL}$ \\
\hline HbA1c (NGSP) & $6.9 \%$ \\
\hline NT-proBNP & $6,749 \mathrm{pg} / \mathrm{mL}$ \\
\hline \multicolumn{2}{|l|}{ Coagulation } \\
\hline PT (INR) & 1.16 \\
\hline APTT & $26.3 \mathrm{~s}$ \\
\hline $\mathrm{D}$ dimer & $4.6 \mu \mathrm{g} / \mathrm{mL}$ \\
\hline \multicolumn{2}{|l|}{ Urine Test } \\
\hline Protein & $(-)$ \\
\hline Glucose & $(-)$ \\
\hline Urine blood & $(-)$ \\
\hline
\end{tabular}

cells and bodies (Fig. 2). Her leukocyte $\alpha$-GAL activity was slightly decreased, $45.5 \mathrm{nmol} / \mathrm{mg}$ (range, 49.8-116.4 nmol/ $\mathrm{mg}$ ). We performed a genetic test and identified a missense heterozygous mutation, c. $395 \mathrm{G} / \mathrm{G}>\mathrm{G} / \mathrm{A}$, p. G132E in GLA. A myocardial biopsy was not performed because she refused invasive tests. The left ventricular apical thrombus disappeared after one month of anticoagulant treatment with warfarin. The patient's symptoms improved, and she was discharged.

The patient had a son and daughter; neither of them had displayed any symptoms and had no particular medical histories. After their mother's diagnosis, they underwent genetic screenings, and the same mutation was found in the daughter only. Echocardiography of the daughter revealed mild left ventricular hypertrophy, while the findings of the son were normal.

\section{Discussion}

Fabry disease is an uncommon X-linked lysosomal storage disorder with a worldwide estimated birth prevalence of 1 in 40,000-117,000 (2). In Japan, a newborn mass screening for Fabry disease showed that the prevalence of patients with pathogenic mutations was 1 in 7,057 (3). Patients with classical type of Fabry disease present with apparent symptoms; however, those with variant type do not show such symptoms. Therefore, the variant types of Fabry disease are difficult to identify and thus are sometimes misdiagnosed.

Mulberry bodies and cells are pathognomonic features of Fabry disease. GL-3 accumulated in proximal tubular epithelial cells is thought to be the source of the mulberry bodies and cells excreted in the urine. Selvarajah et al. showed that both the sensitivity and specificity of urine microscopy for detecting Fabry disease were 100\% (4). Recent case reports have shown that mulberry cell detection is a rapid, inexpensive, and noninvasive tool for detecting Fabry disease (5-7). However, the usefulness of mulberry cells is not widely recognized, in part because the diagnosis depends on the technician's experience and knowledge in detecting such ele-
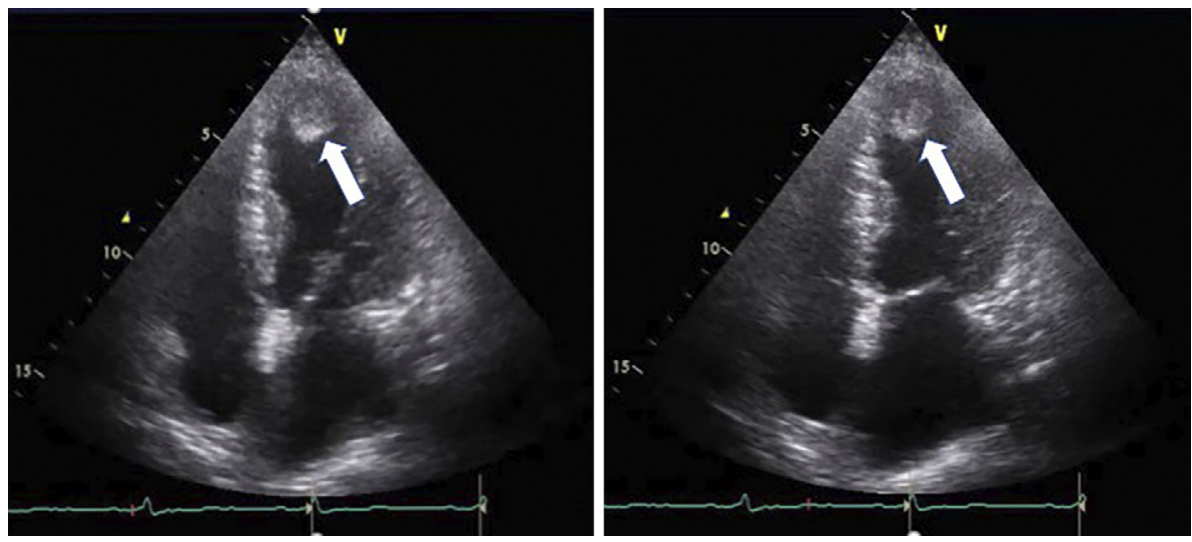

Figure 1. Transthoracic echocardiogram. Apical four-chamber view in end diastole (left side) and systole (right side) showing the thrombus in the apex of the left ventricle (arrow). Echocardiography revealed global left ventricular hypokinesis and no left ventricular hypertrophy. 


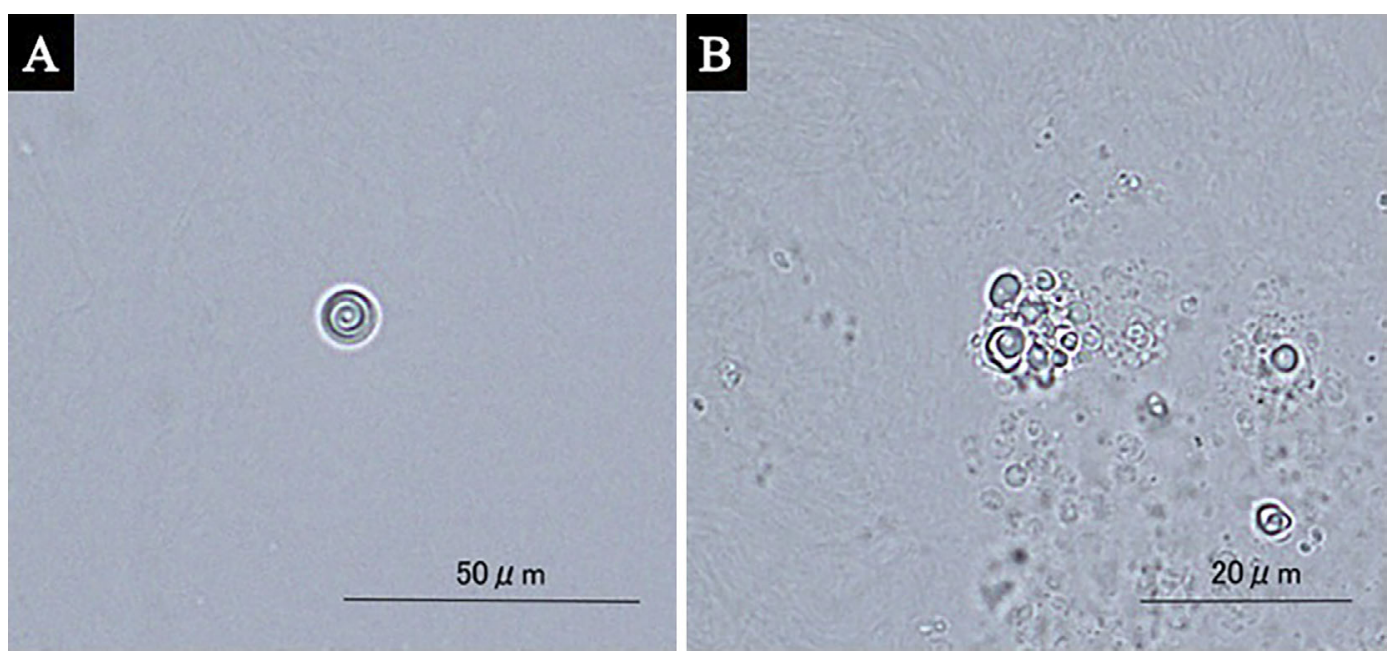

Figure 2. (A) Mulberry body in the urine sediment. Magnification, 400x. Lamellar appearance is the characteristic feature of mulberry bodies. (B) Mulberry cells in the urine sediment. Magnification, 400x.

ments. Nevertheless, we believe that urine microscopy may be a useful tool for the diagnosis of variant-type Fabry disease.

To our knowledge, this is the first report on the cardiac variant of Fabry disease without typical hypertrophy diagnosed by the presence of urinary mulberry cells. Our case has two implications. First, even without typical clinical findings, urinary mulberry cells may indicate Fabry disease as the cause of otherwise unexplained heart failure. In our case, we did not suspect Fabry disease until observing the urinalysis results because echocardiography did not show cardiac hypertrophy, which is one of the common cardiac features of the disease. However, Niemann et al. showed that myocardial hypertrophy is less common in women with Fabry disease than in men (8); thus, a urinalysis may be helpful for diagnosing women with unknown heart failure with or without cardiac hypertrophy. Second, even if the urinary protein test is negative, detecting the presence of urinary mulberry cells is useful for diagnosing Fabry disease. Fabry disease has been detected in patients with renal failure. Shimohata et al. showed the usefulness of mulberry cells in a patient without proteinuria (9). Our results support the notion that testing for mulberry cells is an important screening tool for diagnosing Fabry disease in patients without proteinuria.

Enzyme replacement therapy (ERT) controls the progression of cardiomyopathy in patients with Fabry disease (10) and is recommended when patients have a definite diagnosis of Fabry disease (11). In our patient, ERT was suggested; however, she declined the treatment. Her daughter was diagnosed with Fabry disease, and she underwent ERT. The mutation has not been published in any paper yet. The detection of mulberry bodies enabled us to not only diagnose our patient but also her children; therefore, we were able to initiate appropriate treatment.

\section{Conclusion}

We describe the rare case of a woman with cardiac variant of Fabry disease diagnosed based on the presence of urinary mulberry bodies. Our experience suggests that patients with heart failure without typical symptoms of Fabry disease should undergo screening for urinary mulberry bodies, as it may lead to a diagnosis and help them undergo ERT at an early stage.

The authors state that they have no Conflict of Interest (COI).

\section{References}

1. Zarate YA, Hopkin RJ. Fabry's disease. Lancet 372: 1427-1435, 2008.

2. Mehta A, Ricci R, Widmer U, et al. Fabry disease defined: baseline clinical manifestations of 366 patients in the Fabry Outcome Survey. Eur J Clin Invest 34: 236-242, 2004.

3. Inoue T, Hattori K, Ihara K, Ishii A, Nakamura K, Hirose S. Newborn screening for Fabry disease in Japan: prevalence and genotypes of Fabry disease in a pilot study. J Hum Genet 58: 548-552, 2013.

4. Selvarajah M, Nicholls K, Hewitson TD, Becker GJ. Targeted urine microscopy in Anderson-Fabry disease: a cheap, sensitive and specific diagnostic technique. Nephrol Dial Transplant 26: 3195-3202, 2011.

5. Nakamichi T, Miyazaki M, Nakayama K, et al. Fabry's disease discovered with chance urinary mulberry cells: a case report. CEN Case Rep 2: 49-52, 2013.

6. Honda T, Komatsu E, Furuse S, Mise N. Fabry disease diagnosed based on the detection of urinary mulberry bodies. Intern Med 55: 2903, 2016.

7. Yano T, Takahashi R, Yamashita $\mathrm{T}$, et al. Detection of urinary mulberry bodies leads to diagnosis of Fabry cardiomyopathy: a simple clue in the urine sediment. Circ Heart Fail 10: 2017.

8. Niemann M, Herrmann S, Hu K, et al. Differences in Fabry cardiomyopathy between female and male patients: consequences for diagnostic assessment. JACC Cardiovasc Imaging 4: 592-601, 2011.

9. Shimohata H, Ogawa Y, Maruyama H, Hirayama K, Kobayashi M. 
A renal variant of Fabry disease diagnosed by the presence of urinary mulberry cells. Intern Med 55: 3475-3478, 2016.

10. Kampmann C, Perrin A, Beck M. Effectiveness of agalsidase alfa enzyme replacement in Fabry disease: cardiac outcomes after 10 years' treatment. Orphanet J Rare Dis 10: 125, 2015.

11. Biegstraaten M, Arngrímsson R, Barbey $F$, et al. Recommendations for initiation and cessation of enzyme replacement therapy in patients with Fabry disease: the European Fabry Working Group consensus document. Orphanet J Rare Dis 10: 36, 2015.

The Internal Medicine is an Open Access journal distributed under the Creative Commons Attribution-NonCommercial-NoDerivatives 4.0 International License. To view the details of this license, please visit (https://creativecommons.org/licenses/ by-nc-nd/4.0/).

(C) 2018 The Japanese Society of Internal Medicine Intern Med 57: 3385-3388, 2018 